\title{
Interactive Multimedia Material for an Electrical Power Quality Course
}

\author{
P.G. MARAMBEAS, P. STERGIOPOULOS, S. PAPATHANASIOU, P. BAUER, S.N. MANIAS \\ Department of Electrical and Computer Engineering \\ 9 Iroon Polytechniou 15773 Athens \\ GREECE \\ manias@central.ntua.gr http:/www.ntua.gr
}

\begin{abstract}
The aim of this paper is to present an interactive multimedia material, which can assist to the educational environment of electrical power quality courses and especially to those, which do not include laboratory exercises. This computer interactive multimedia course, which can be executed on any modern personal computer without any additional hardware or software, includes general power quality definitions, harmonic analysis, calculation of Total Harmonic Distortion (THD), power factor correction, passive filters, resonance phenomena, operation of active filters, operation of active voltage regulators, and operation of state of the art inverters. Finally, the contents of the proposed e-learning material will be presented and the implementation of some key interactive animations will be explained and analyzed.
\end{abstract}

Key-Words: - Interactive animations, power quality, inverters, harmonics, passive filtering, active filtering.

\section{Introduction}

Power quality phenomena include all possible situations in which the waveform of the network voltage (voltage quality) or load current (current quality) deviate from an ideal sinusoidal waveform at rated conditions. For these reasons, today there is a growing interest to study the sources that create power quality disturbances and the techniques that are used to eliminate them [1]-[2]. In electrical power quality courses, there are a number of concepts that students traditionally have difficulty to understand because they are not so easy to be visualized. Students tend to view a course in electrical power quality as a dry experience, which does not go beyond mathematical manipulations and control techniques. These include phenomena on transmission and distribution systems such as harmonic creation, harmonic mitigation techniques, resonance phenomena, active regulation techniques, passive filtering and active filtering.

Today there are the following three e-learning approaches, which can be used for course teaching assistance:

a) intensive use of slide show presentations,

b) creation of e-learning modules such as interactive

flash animations, dynamic Web pages, or Java applets, and

c) video lectures.

Slide show presentations enable good visualization and smooth lecture performance where visual elements such as tables, diagrams, or images can be directly presented statically to the students. Video lectures let the students follow a particular lecture remotely and recall previous sessions. Flash interactive animations or Java applets are used for presentation as well as for individual training by the students at home. With modern computer hardware and software tools, interactive animations can be readily produced, and have been used to demonstrate power and power electronics circuits. At this point it is very important to mention that interactive animations are only used for visualizing a particular concept and are not replacing the theoretical and simulation analysis of a power or power electronics topology.

Although e-learning material can be a useful didactic tool, the professors should retain control over the amount, order, and elements of material to be included in the lecture.

The technology has reached the point where it is feasible to both create and use interactive animations in order to teach the difficult concepts of a specific course [3]-[8]. It has been found that students who are faced with principles of electrical power quality have problems in understanding and dealing with the high complexity of these systems and specifically when their course does not include laboratory or simulation exercises.

The resources required to create animations for multimedia material are not expensive. Aside from the operating system, the software programs used to create the animations are available free from Internet sites. For the implementation of the proposed multimedia material the Macromedia and HTML software programs were used. The hardware required in order to execute these programs are 
typical computing facilities widely available today. The contents of the proposed multimedia material include the following topics:

1) Electrical power quality definitions

2) Power Factor Correction

3) Harmonic analysis

4) Passive resonant and low pass filters

5) Resonance phenomena

6) Parallel and Series Active filters

7) Power electronics inverters

Finally, in the next section a number of animations are presented, which were created for the proposed multimedia course.

\section{Proposed Animations}

In this section some of the animations of the proposed multimedia material will be presented and analyzed in the sequence they appear in the course. At this point it should be mentioned, that each animation (main screen or slide) is supported by one or more screens. These supporting screens provide very short definitions, some useful equations or explanatory schematics (secondary or supported screen). Fig.1 shows two ((a), (b)) selected structures of the main screens and supported screens, which were used to implement the proposed multimedia teaching material. Fig. 2 shows examples of such secondary screens.

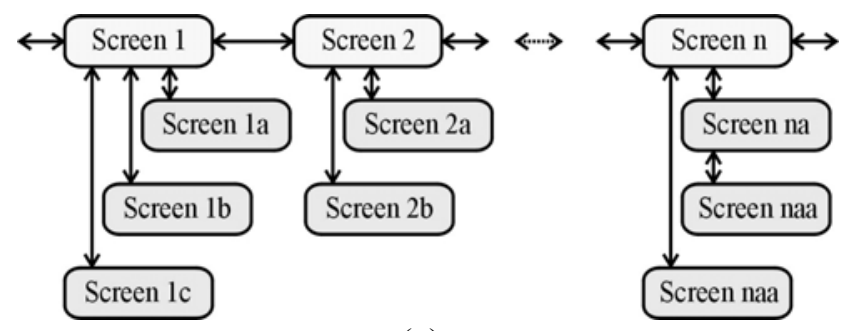

(a)

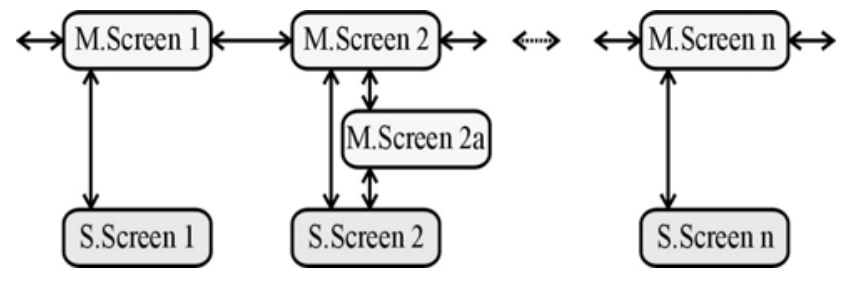

(b)

Fig.1 Structures of main and supported slides or screens used for the implementation of the proposed e-learning material.

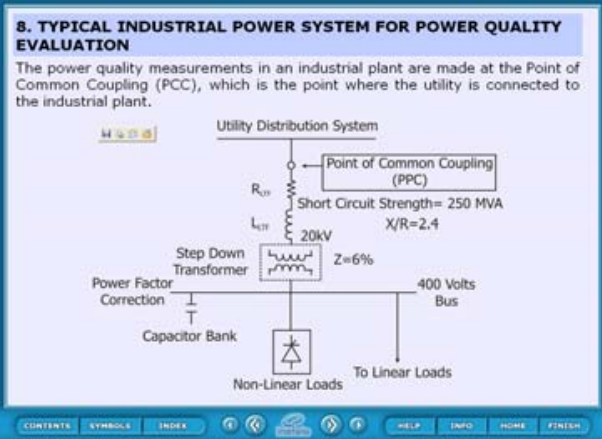

(a)

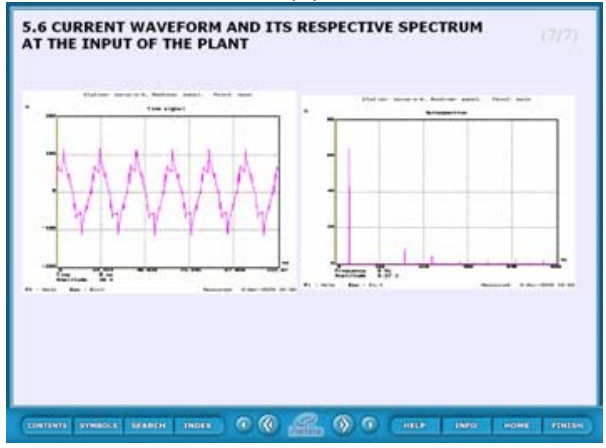

(b)

Fig.2 Typical slides of the multimedia course that provide some additional basic information. a)Schematic of an industrial power system b)Current waveform in an industrial plant and its respective spectrum

\subsection{Harmonic Analysis Interactive Animations}

In electrical power quality theory one of the basic mathematics that a student must know is the Fourier series analysis of voltage and current waveforms. The interactive animations, which were implemented in order to cover the harmonic analysis using Fourier series, are based on the following relations:

$$
\begin{aligned}
& \mathrm{f}(\mathrm{t})=\mathrm{F}_{\mathrm{o}}+\sum_{\mathrm{n}=1}^{\infty} \mathrm{a}_{\mathrm{n}} \sin \mathrm{n} \omega \mathrm{t}+\sum_{\mathrm{n}=1}^{\infty} \mathrm{b}_{\mathrm{n}} \cos \mathrm{n} \omega \mathrm{t} \\
& \mathrm{a}_{\mathrm{n}}=\frac{1}{\pi} \int_{0}^{2 \pi} \mathrm{f}(\mathrm{t}) \sin \mathrm{n} \omega \mathrm{td}(\omega \mathrm{t})=\frac{2}{\pi} \int_{0}^{\pi} \mathrm{f}(\mathrm{t}) \sin \mathrm{n} \omega \mathrm{td}(\omega \mathrm{t}) \\
& \mathrm{b}_{\mathrm{n}}=\frac{1}{\pi} \int_{0}^{2 \pi} \mathrm{f}(\mathrm{t}) \cos \mathrm{n} \omega \mathrm{td}(\omega \mathrm{t})=\frac{2}{\pi} \int_{0}^{\pi} \mathrm{f}(\mathrm{t}) \cos \mathrm{n} \omega \mathrm{td}(\omega \mathrm{t}) \\
& \text { Fo }=\text { average value of } \mathrm{f}(\mathrm{t})=\frac{1}{2 \pi} \int_{0}^{2 \pi} \mathrm{f}(\mathrm{t}) \mathrm{d}(\omega \mathrm{t})
\end{aligned}
$$

For the implementation of the interactive calculations of the Total Harmonic Distortion (THD) factor, the Harmonic Factor, and the RMS value of a waveform $f(t)$, the following relations are used: 
THD $\%$ of the waveform $\mathrm{f}(\mathrm{t})=\frac{\left[\sum_{\mathrm{n}=2,3,4,}^{\infty} \tilde{\mathrm{F}}_{\mathrm{n}}^{2}\right]^{1 / 2}}{\tilde{\mathrm{F}}_{1}} \times 100$

$\mathrm{HF}=$ Harmonic Factor of the waveform $\mathrm{f}(\mathrm{t})=\frac{\left[\sum_{\mathrm{n}=1,2,3}^{\infty} \tilde{\mathrm{F}}_{\mathrm{n}}^{2}\right]^{1 / 2}}{\tilde{\mathrm{F}}_{1}}$

$\tilde{\mathrm{F}}=$ RMS value of the waveform $\mathrm{f}(\mathrm{t})=\left[\sum_{\mathrm{n}=1,2,3}^{\infty}{\tilde{\mathrm{F}_{n}}}^{2}\right]^{1 / 2}$

Where,

$\tilde{\mathrm{F}}_{\mathrm{n}}=\mathrm{RMS}$ value of the nth harmonic component. When a passive RL load is fed by a distorted voltage, then the amplitude of the load current harmonic components are given by :

$$
\begin{aligned}
\mathrm{I}_{0, \mathrm{n}} & =\mathrm{RMS} \text { value of the current } \mathrm{nth} \text { harmonic component }= \\
& =\frac{\left|\tilde{\mathrm{V}}_{0, \mathrm{n}}\right|}{\left|\mathrm{Z}_{\mathrm{n}}\right|}
\end{aligned}
$$

Where, $\left|Z_{n}\right|=\sqrt{\mathrm{R}^{2}+(\mathrm{n} \omega L)^{2}}$

Also, for the implementation of the interactive power calculations for a non-linear load that is fed by a pure sinusoidal voltage waveform the following relations were used:

$$
\begin{array}{r}
\mathrm{P}=\text { Real power }=\tilde{\mathrm{V}}_{\mathrm{m}} \tilde{\mathrm{I}}_{1} \cos \varphi_{1} \quad(\mathrm{Watt}) \\
\mathrm{Q}=\text { Reactive power }=\tilde{\mathrm{V}}_{\mathrm{m}} \tilde{\mathrm{I}}_{1} \sin \varphi_{1}(\mathrm{VAR}) \\
\mathrm{S}_{1}=\text { Fundamental apparent power }=\sqrt{P^{2}+Q^{2}}(\mathrm{VA}) \\
\mathrm{D}=\text { Distortion Power }=\tilde{\mathrm{V}}_{\mathrm{m}} \cdot \sqrt{\tilde{\mathrm{I}}_{2}^{2}+\tilde{\mathrm{I}}_{3}^{2}+\tilde{\mathrm{I}}_{4}^{2}+\cdots \tilde{\mathrm{I}}_{\mathrm{n}}^{2}}(\mathrm{VA})
\end{array}
$$

$$
\begin{aligned}
\mathrm{S} & =\text { Total apparent power }=\tilde{V}_{\mathrm{m}} \tilde{I}_{\mathrm{m}}= \\
& =\sqrt{P^{2}+Q^{2}+D^{2}} \quad \mathrm{VA}
\end{aligned}
$$

True Power Factor $=\frac{\mathrm{P}}{\mathrm{S}}=\frac{\tilde{\mathrm{V}}_{\mathrm{m}} \tilde{\mathrm{I}}_{1} \cos \varphi_{1}}{\tilde{\mathrm{V}}_{\mathrm{m}} \tilde{\mathrm{I}}}=$

$$
=\frac{\tilde{\mathrm{I}}_{1}}{\sqrt{\tilde{\mathrm{I}}_{1}^{2}+\tilde{\mathrm{I}}_{2}^{2}+\cdots \tilde{\mathrm{I}}_{\mathrm{n}}^{2}}} \cos \varphi_{1}
$$

Where,

$\tilde{\mathrm{I}}_{1}=$ RMS value of the current fundamental component

$\tilde{\mathrm{V}}_{1}=$ RMS value of the voltage fundamental component

$\varphi_{1}=$ Phase displacement between voltage and current fundamental component

$\tilde{\mathrm{I}}=\mathrm{RMS}$ value of the current

$\tilde{\mathrm{V}}_{\mathrm{m}}=\mathrm{RMS}$ value of the voltage
$\tilde{\mathrm{I}}_{\mathrm{n}}=\mathrm{RMS}$ value of the $\mathrm{nth}$ current harmonic component.

One of the most common waveform of non-linear loads and in power electronics inverter topologies is the square wave, which may represent the inputcurrent of a rectifier or the output voltage of a voltage source inverter. Fig. 3 shows the slide of an interactive animation, which can assist the student to get familiar with the Fourier series analysis or synthesis of a waveform of this type. The user by selecting a certain number of harmonic components can synthesize a number of waveforms.

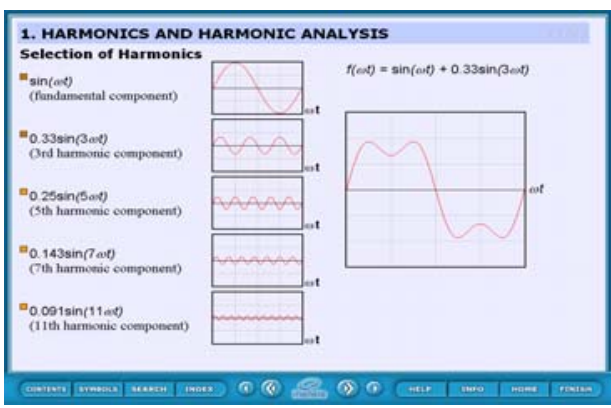

Fig.3 Slide of the interactive harmonic analysis animation of a square wave.

Fig. 4(a) shows the slide of an animation, where by applying a square wave voltage to an R-L load, then the frequency spectrum of the load voltage and the resulting current are calculated. The user has the opportunity to change interactively the amplitude, the pulse width and the R-L values. Moreover, fig. 4(b) shows the slide of an interactive calculation that computes the THD and the RMS value of the harmonic content of a square wave waveform.

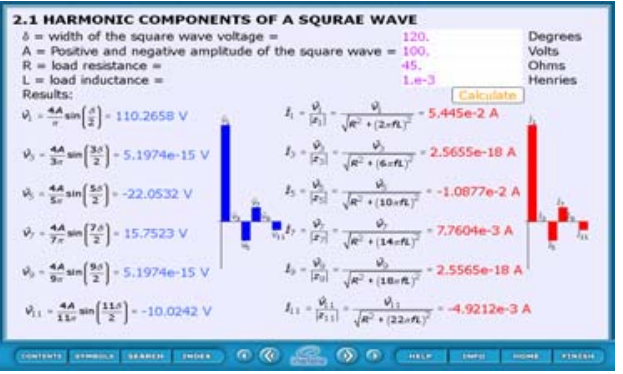

(a)

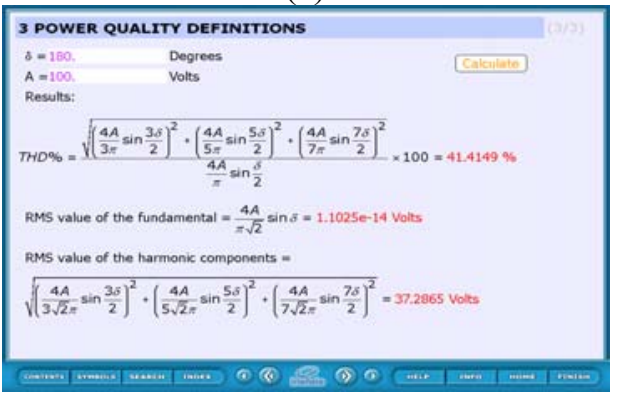

(b)

Fig. 4 Slides of interactive calculations.

a) For harmonic components

b) For THD and harmonic content 
Positive, negative, and zero sequence voltage harmonic components are those components that when are applied to electrical motors, can create torque harmonic components. These voltage harmonic components, which have a particular frequency, try to rotate the motor forward or backward or neither (just heats up the motor).

The harmonic components of a three-phase system are given by:

$$
\begin{aligned}
& \mathrm{v}_{\mathrm{a}, \mathrm{n}}(\omega \mathrm{t})=\mathrm{V}_{\mathrm{n}} \sin (\mathrm{n} \omega \mathrm{t}) \\
& \mathrm{v}_{\mathrm{b}, \mathrm{n}}(\omega \mathrm{t})=\mathrm{V}_{\mathrm{n}} \sin \left[\mathrm{n}\left(\omega \mathrm{t}-\frac{2 \pi}{3}\right)\right] \\
& \mathrm{v}_{\mathrm{c}, \mathrm{n}}(\omega \mathrm{t})=\mathrm{V}_{\mathrm{n}} \sin \left[\mathrm{n}\left(\omega \mathrm{t}+\frac{2 \pi}{3}\right)\right]
\end{aligned}
$$

Where,

$\mathrm{n}=$ the order of the harmonic component $=1,2,3$,

Depending on the value of $\mathrm{n}$, the phase voltages form a positive, a negative or a zero sequence harmonic component. When $\mathrm{n}=3 \mathrm{k}-1$ ( $\mathrm{k}=$ integer) then the phase voltages form a negative sequence harmonic component, when $\mathrm{n}=3 \mathrm{k}+1$ then form a positive sequence harmonic component and when $n$ $=3 \mathrm{k}$ then the phase voltages form a zero sequence harmonic component. For example the triple harmonic components (i.e. $3^{\text {rd }}, 9^{\text {th }}, 15^{\text {th }}, \ldots$ ) are not rotating with the respect to the fundamental component (since $3 \times 0^{\circ}, 3 \times 120^{\circ}=0^{\circ}, 3 \times$ $240^{\circ}=720^{\circ}=0^{\circ}$ ) and consequently are the so called zero sequence harmonic components. According to this theory the animation of fig. 5 was constructed, which can assist the students to understand the difference between the positive and negative sequence harmonics.

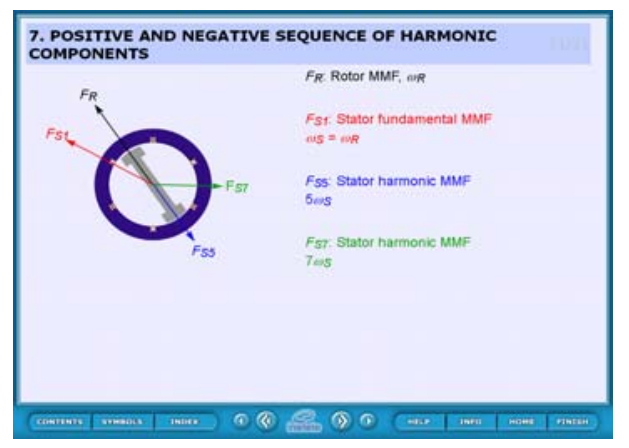

Fig.5 Slide of the animation for visualizing the rotation of positive and negative sequence harmonic MMFs in an electrical machine.

\subsection{Active Filter Interactive Animation}

Interactive animations and diagrams allow the students to actually see on a computer screen how active power filters operate and consequently help them to more easily understand the theoretical part of a power quality course. Such interactive animations are the ones shown in figs 6 and 7. The active filters are implemented using semiconductor devices and particularly power electronics inverter topologies [9]-[10]. There are two basic types of active filters; the parallel active filter, which is placed in parallel to the AC network line and the series active filter, which is placed in series with the $\mathrm{AC}$ network line through a power transformer. The active filters are used for voltage and current harmonics mitigation and power factor conditioning. Fig. 6 shows the slide of an interactive animation of a parallel active filter, where the user by selecting a number of load current harmonics can visualize the respective current waveform of the load, as well as the current waveform of the active filter, that needs to be injected in order to compensate the load current harmonics and thus produce a sinusoidal source current waveform.

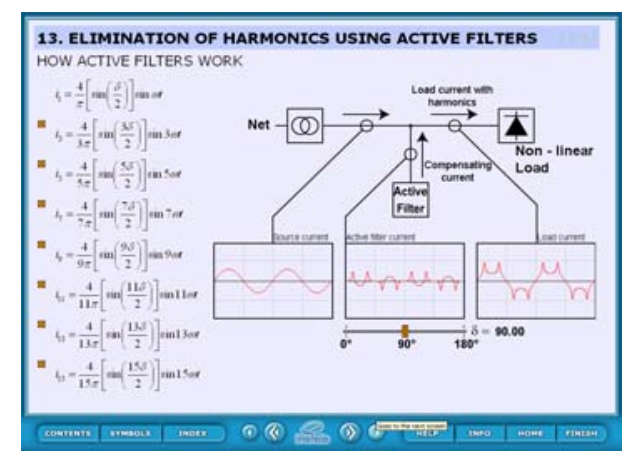

Fig.6 Slide of interactive animation slide of a shunt active filter.

Fig.7 shows the slide of a series active filter animation, which is used for mitigation of load voltage harmonics as well as for load voltage regulation.

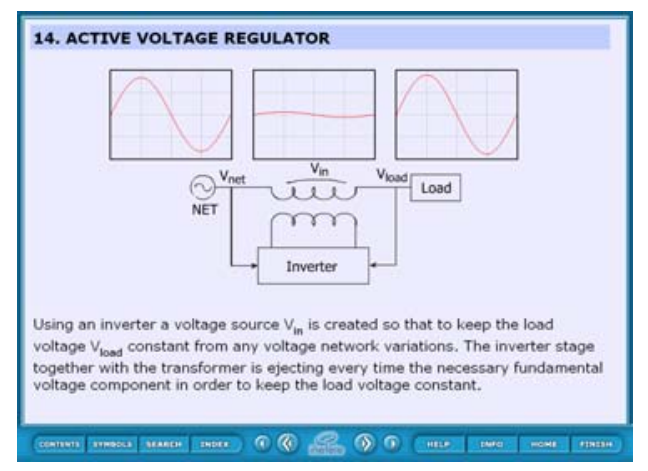

Fig.7 Interactive animation slide of a series active filter or active voltage regulator.

In both animations the main component of the active filters is a power inverter topology, which converts a DC voltage to single-phase or three-phase AC voltage. 


\subsection{Inverter Interactive Animations}

As it was mentioned before, the main component of an active power filter is the power inverter. For electrical power quality applications, there are mainly two types of inverters used; the two-level and the multilevel topologies. The two level inverter topologies, which are used in low to medium power range of applications, generate an output phase voltage waveform that is consisted of only two voltage levels. The multilevel inverter topologies [11], which are used for high voltage, high power applications, generate at their output phase voltage waveforms with more than two levels. Figs 8 and 9 show the interactive animations of these dc-ac converters. Fig. 8 shows the animation of a singlephase inverter and its operation flowchart, which was used to implement this animation. In fig. 8 the user can select the operation point of interest of the inverter (output voltage and current values), then can see on the computer screen the current path of the inverter and the semiconductor devices that are conducting at this point of operation. Fig. 8(b) shows the flowchart of the operation modes of the two-level inverter, which was used to implement this particular animation. Fig. 9 refers to a 5-level multilevel-cascaded inverter that uses the sinusoidal pulse width modulation (SPWM) control technique. The output voltage levels, which are created by the 5-level SPWM inverter, are $0,+\mathrm{V},+2 \mathrm{~V},-\mathrm{V}$ and $2 \mathrm{~V}$. This inverter is implemented using two inverter modules of fig. 8 and connecting their output in series. In order to create the voltage levels $+\mathrm{V}$ or $-\mathrm{V}$ the bottom inverter module is operating such that to generate these output voltage levels, while at the same time the top inverter module is operating in the so called freewheeling mode, providing a path for the load current with zero output voltage. In order to create the voltage levels $+2 \mathrm{~V}$ or $-2 \mathrm{~V}$, both inverter modules are operating such that each one creates $\mathrm{a}+\mathrm{V}$ or $-\mathrm{V}$ output voltage level. In order to create a zero output voltage level, then both inverter modules must operate in the freewheeling mode, providing a path for the load current to circulate and at the same time creating a zero output voltage. The user, by selecting the operation point of interest can watch the current path and the conducting semiconductor devices.

Fig. 9(b) shows the flowchart of the operation modes of the 5-level SPWM cascaded inverter, which was used to implement the animation.

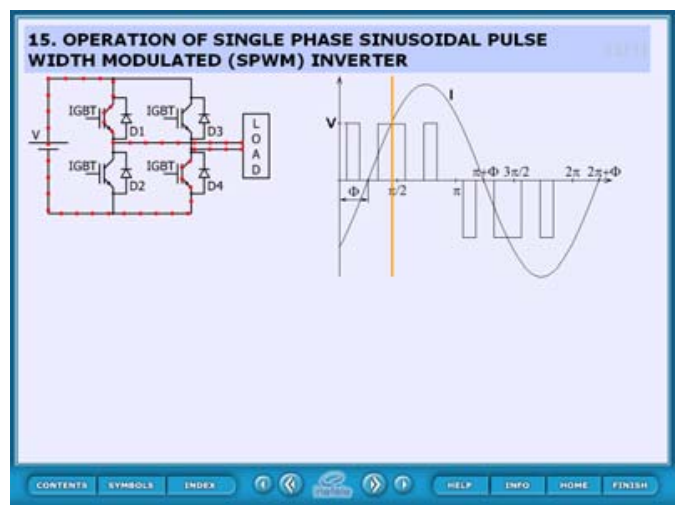

(a)

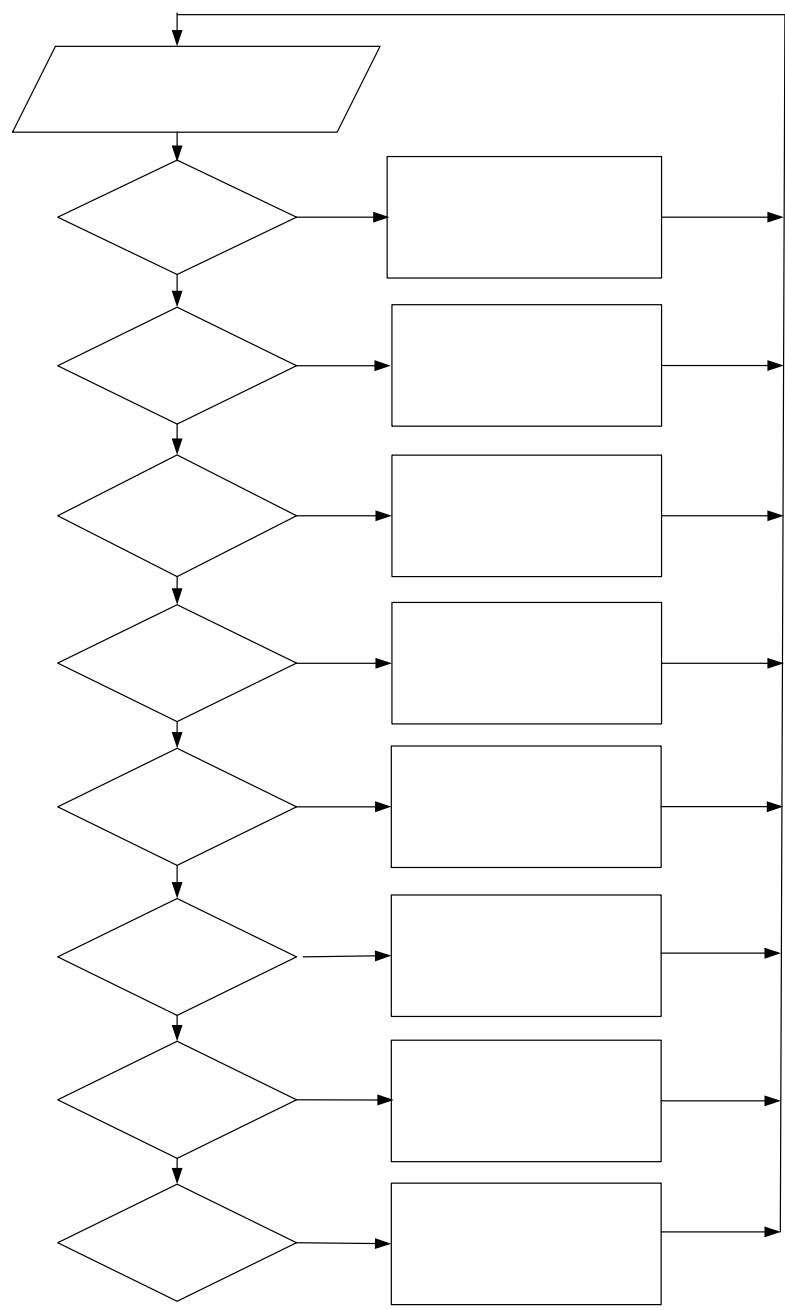

(b)

Fig.8: Interactive animation of a single-phase twolevel voltage source sinusoidal pulse width modulated inverter.

a) Slide of the animation

b) Flowchart of the operating states or modes of the inverter 


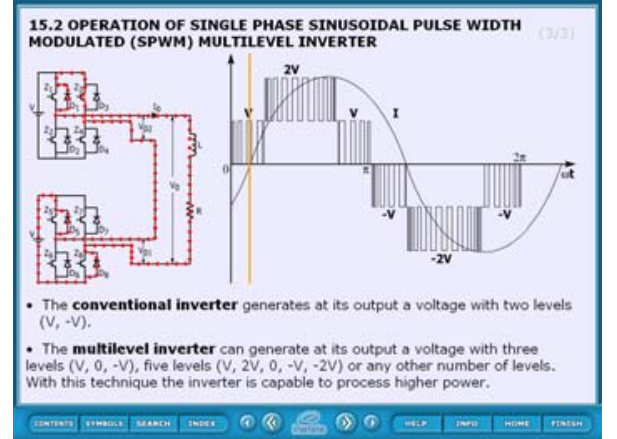

(a)

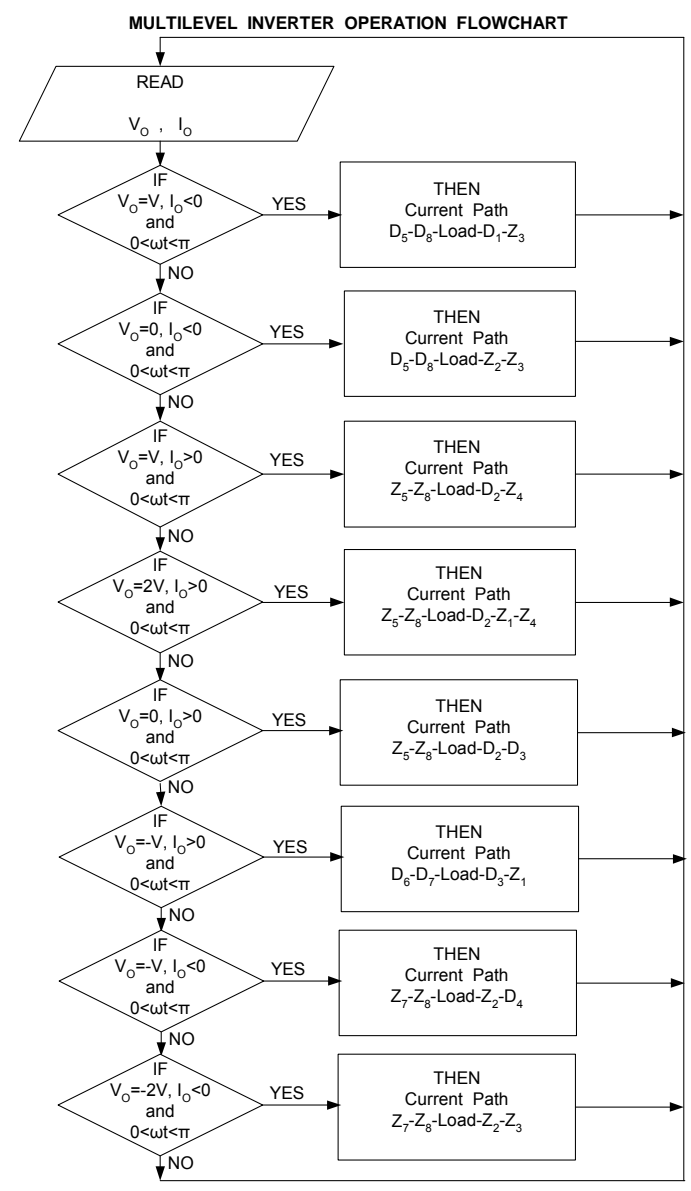

(b)

Fig.9 Interactive animation of a single-phase multilevel (5-level) voltage source sinusoidal pulse width modulated inverter.

a) Slide of the animation

b) Flowchart of the inverter operating states

\section{Conclusion}

In this paper a multimedia course for an electrical power quality course was presented, which can be used as additional educational material for the visualization and understanding phenomena of an electrical power quality course. A number of computer animations were presented and analyzed, which can assist to the educational environment of an electrical power quality course and especially in the absence of suitable laboratory exercises. In order to implement these animations, software packages available free-of-charge from the Internet was used. The computer animations included harmonic analysis, resonance phenomena, active harmonic elimination, active voltage regulation, and inverter operation. These animations have already been utilized in undergraduate electrical engineering courses and a very positive feedback was received from the students.

\section{References:}

[1] ] J. Arriilaga, D.A. Bradley, and P.S. Bodger, "Power System Harmonics", New York: Wiley, 1985.

[2] N. Shepherd and P. Zand, "Energy flow and power factor in nonsinusoidal circuits", Cambridge University Press, 1979.

[3] U. Drofenic, et al, "New Web-Based Interactive E-learning in Power Electronics and Electrical Machines", IEEE IAS conference, 2001, pp. 7803-7116.

[4] U. Drofenic and J. Kolar, "Interactive Power Electronics Seminar (IPES)-A Web-Based introductory Power Electronics course employing Java-Applets", IEEE PESC conference, 2002, pp. 443-448.

[5] C.R. Sullivan, "Three dimensional Animations to visualize voltage and current", IEEE PESC conference, 2003, pp. 466-473.

[6] V.G. Agelidis "The future of power engineering education: challenges and opportunities", IEEE PESC conference, 2005, pp. 1-6.

[7] A. McGettrick et al, "Computer Engineering Curriculum in the new Millennium", IEEE Transactions on education, Vol. 46, No. 4, Nov. 2003, pp. 452-455.

[8] A. Hoyer et al, "A multi-user Virtual-Reality Environment for a Tele-Operated Laboratory", IEEE Transactions on education, Vol. 47, No. 1, Feb. 2004, pp.121-126.

[9] H. Akagi, "New trends in active filters for Power conditioning", IEEE Trans. on Industry Applications, Vol. 32, Nov/Dec. 1996, pp. 1312-1322.

[10] B. Singh et al, "A Review of Active Filters for Power Quality Improvement”, IEEE Trans. on Industrial Electronics, Vol. 46, No. 5, Oct. 1999, pp. 960-971.

[11] M. H. Rashid, Power Electronics, Prentice Hall, 2004. 